\title{
Study on Safety and Efficacy of Deferasirox in the treatment of Thalassemia in a South Indian Tertiary Care Hospital
}

\author{
Siva Shankar Reddy $\mathbf{Y}^{*}$, Umesh Kamrthi ${ }^{2}$ and Balasubramanian Kumar ${ }^{3}$ \\ 1'Department of Pharmacy Practice, Ratnam Institute of Pharmacy, Nellore, A.P, INDIA. \\ ${ }^{2}$ Clinical Pharmacist in BGS Global Hospitals, Kengeri, Bangalore, Karnataka, INDIA. \\ ${ }^{3}$ Department of Pharmacy Practice, Ratnam Institute of Pharmacy, Nellore, INDIA.
}

\begin{abstract}
Background: There were very less number of research studies been done in Indian settings or around the world about the efficacy and safety of Deferasirox in thalassemia patients. The objective of this study was to assess the efficacy and safety of Deferasirox in thalassemia patients. Methodology: It is a prospective, observational study conducted for a period of eight months that assessed the laboratory data of thalassemia patients aged $\leq 15$ years who were on Deferasirox therapy. The study was conducted in a tertiary care hospital situated in Nellore Andhra Pradesh, India. The study involved the day-to-day review of medication orders and laboratory data in the pediatrics wards. Evaluation included the collection of laboratory data such as serum ferritin levels for the efficacy assessment and alanine transaminase (ALT), serum creatinine, White Blood Cells (WBC) counts and platelet counts for safety assessment. Results: Total numbers of patients enrolled in the study were twenty-four out of 63 thalassemia patients treated in the hospital. Efficacy outcomes resulted that 18 (75\%) out of 24 patients responded positively to the Deferasirox, whereas remaining $6(25 \%)$ patients were observed with no changes in their serum ferritin levels. The safety outcomes stated that $11(45.83 \%)$ out of 24 patients were observed with increased ALT levels whereas, the other safety parameters such as serum creatinine, WBCs and platelet counts were observed to be with mild deviations causing no clinical harm to the patients. Conclusion: This study has shown a consistent efficacy in $75 \%$ of patients and a manageable safety profile. Thus, it demonstrates that the oral chelation therapy of Deferasirox was efficient and well tolerated, especially in moderately iron loaded transfusion-dependent thalassemia patients.
\end{abstract}

Key words: Alanine transaminase (ALT), Deferasirox, Iron chelating agent, Iron overload, Thalassemia patients.

\section{INTRODUCTION}

Only few studies were carried out on the efficacy and safety evaluation of Deferasirox in India or around the world. Chronic iron overload represents a serious complication of potentially life-saving regular blood transfusions which are administered for a variety of congenital and acquired types of anemia. Iron from frequent blood transfusions deposits mainly in the liver, endocrine organs, and heart. ${ }^{1,2}$ Patients with chronic anemia such as thalassemia, sickle cell disease, congenital rare anemia and myelodysplastic syndromes require regular blood transfusions in order to improve both Quality of Life (QOL) and survival.
Human body is unable to eliminate the iron released from the breakdown of transfused red blood cells and the excess iron is deposited as hemosiderin and ferritin in the liver, spleen, endocrine organs and myocardium. ${ }^{3}$ The accumulation of toxic quantities of iron causes tissue damage and leads to complications such as heart failure, diabetes, hypothyroidism, liver failure and early death. ${ }^{3,4}$ Morbidity and mortality in regularly-transfused thalassemia patients are primarily due to the effects of iron overload rather than to the underlying disease, with over half of all deaths attributable to cardiac complications. ${ }^{3}$ Packed Red Blood
Submitted date :02-Feb-2015 Accepted date :11-Mar-2015

DOI: $10.5530 /$ ijopp.8.1.5

Address for correspondence: Mr. Siva Shankar Reddy $Y$, M. Pharm (Pharmacy practice), Department of Pharmacy Practice,

Ratnam Institute of Pharmacy, Nellore, A.P, INDIA.

E-mail:ysrkurnool@gmail.com 


\section{SAFETY AND EFFICACY OF MEDICINE DEFERASIROX USED IN THE TREATMENT OF THALASSEM IA}

PATIENTS IN A SOUTH INDIAN TERTIARY CARE HOSPITAL

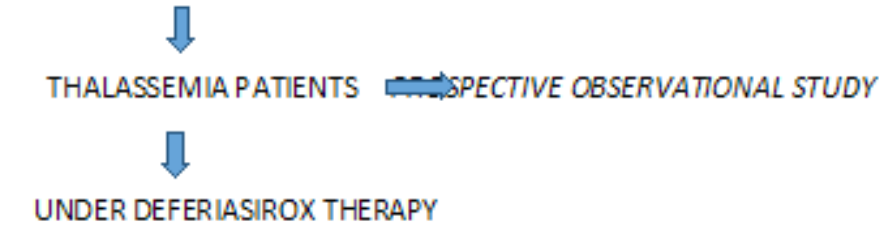

DAY TO DAY REVIEW OF MEDICATIONS

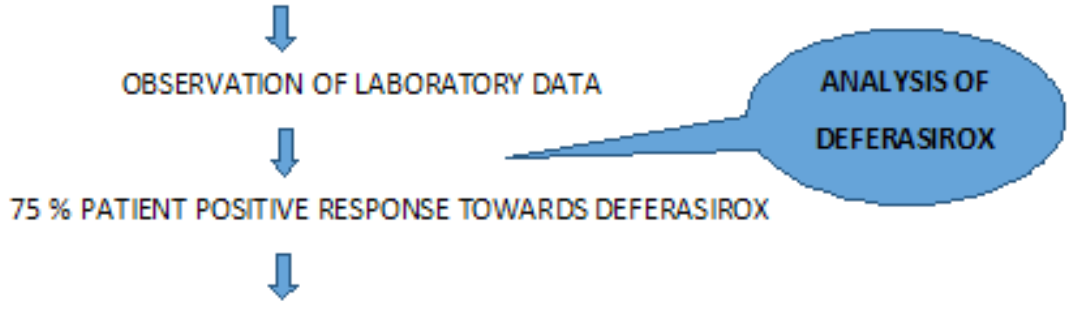

BY THE DEFERASIROX, ORAL CHELATION THERAPY WAS OBSERVED SAFETY AND EFFECTIVE

\section{Graphical Abstract}

Cells (PRBC) contain approximately $1 \mathrm{mg}$ of elemental iron per ml. Evidence of iron overload is generally apparent after about 100 to $120 \mathrm{ml} / \mathrm{kg}$ of PRBC have been administered which is equivalent to 20 to 30 adult units. $^{5-7}$ In frequently transfused thalassemia patients, the total body iron burden is estimated to increase at a rate of 2 to 5 grams of iron per year. ${ }^{5}$ The accumulation of iron in the body is reflected by a measurable increase in serum ferritin levels. Increased morbidity and mortality are observed in patients with serum ferritin values above $2500 \mathrm{ng} / \mathrm{ml}^{4}{ }^{4}$ In the absence of chelation therapy, iron overload leads to the development of multi-system organ dysfunction, ultimately concluding in death in all patients. ${ }^{8}$ Without chelation therapy, patients generally develop cirrhosis between the ages of 10 to 15 years, but mild cirrhosis has been observed as early as 8 or 9 years of age. ${ }^{9}$ Endocrine complications including pituitary and gonadal failure are common even early in life leading to growth failure and delayed development of secondary sexual characteristics. The development of diabetes mellitus by early in the second decade of life is frequent. Cardiac complications, often manifest as congestive heart failure, have a peak incidence between the ages 10 to 15 years. ${ }^{5,10}$ Consequently, regularly transfused patients with $B$-thalassemia major who do not receive or who do not comply with chelation therapy to remove excess iron do not survive past the third decade of life due to the cumulative toxic effects of iron resulting in organ failure. A variety of epidemiological data are consistent and indicates that in the absence of good compliance with an adequate regimen of chelation therapy, cardiomyopathy attributable to iron over- load is the most frequent cause of death in patients with $\beta$-thalassemia major. ${ }^{5,11}$ Diseases such as $\beta$-thalassemia, once fatal in early childhood, can now be managed as chronic conditions compatible with prolonged life with life expectancy varying between 25 and 55 years, depending on patients' compliance with medical treatment, particularly iron chelation therapy. ${ }^{12}$ The efficacy and safety profiles of Deferasirox have been studied in a series of 1-year Phase II and III registration studies involving more than 1,000 patients, including 433 patients aged between 2 to 15 years. These studies led to Food and Drug Administration (FDA) approval of Deferasirox with an orphan drug designation. In clinical trials, Deferasirox has demonstrated consistent dosedependent efficacy, producing sustained reductions in serum ferritin, labile plasma iron, and cardiac iron load. Some of the Phase II and III registration studies conducted on Deferasirox described a defined, clinically manageable safety profile across all age groups, including patients as young as 2 years of age. Across the core trials, the most common drug-related adverse events were gastro-intestinal disturbances and rashes. ${ }^{13-15}$ Nonprogressive increases in serum creatinine were observed in approximately one-third of patients treated with Deferasirox. ${ }^{14}$ These increases were dose dependent, often resolved spontaneously and could sometimes be alleviated by reducing the dose. ${ }^{15}$

In order to get further supportive evidences in the Indian setup, this study was conducted involving the assessment of efficacy and safety of Deferasirox in the thalassemia patients been treated in a tertiary care hospital situated in Nellore Andhra Pradesh, India.

Indian Journal of Pharmacy Practice, Vol 8, Issue 1, Jan-Mar, 2015 


\section{METHODOLOGY}

Study Design: It was a prospective, observational study thatassessed the laboratory data of thalassemia patients who were on Deferasirox therapy and evaluated the efficacy and safety of Deferasirox in those patients.Total numbers of patients enrolled in this study were twentyfour (17 male and 7 female) out of 63 thalassemia patients treated in the hospital. A written informed consent was obtained from each patient's legally acceptable representative prior to the initiation of any study data collection. The study involved a day-to-day review of medication orders and laboratory data in the pediatrics wards. Each patient received PRBC transfusions at one to two week intervals to maintain the hemoglobin concentration at a level above $10 \mathrm{gm} / \mathrm{dl}$. The initial dose of Deferasirox was individualized according to blood transfusion frequency, generally given in the morning. The recommended initial dose of Deferasirox was $20 \mathrm{mg} / \mathrm{kg}$ per day for patients receiving approximately 6 to 8 units of PRBC per month, which could be discontinued or adjusted in increments of 5 to $10 \mathrm{mg} / \mathrm{kg}$ per day when necessary based on serum ferritin levels and safety markers (serum creatinine, ALT levels, WBC counts and platelet counts). If serum ferritin levels fell down below $1000 \mathrm{ng} / \mathrm{ml}$ on two consecutive study visits, Deferasirox treatment was discontinued until levels exceeded $1000 \mathrm{ng} / \mathrm{ml}$.

Study Site: The study was conducted in the Department of Pediatrics of a tertiary care hospital situated in Nellore Andhra Pradesh, India.

Study Period: The study was conducted for the period of eight months from June 2014 to January 2015.

\section{Study Criteria}

Inclusion criteria: Male or female pediatric patients (age, $\leq 15$ years) with transfusional iron overload were included in the study if they fulfilled the following criterion:

- Serum ferritin levels $\geq 1000 \mathrm{ng} / \mathrm{ml}$, or $<1000 \mathrm{ng} /$ $\mathrm{ml}$ but with a medication history of Deferasirox.

- Patients diagnosed with thalassemia and enrolled on a Hyper-transfusion Program with confirmed annual blood transfusion of $100 \mathrm{ml} / \mathrm{kg} /$ yearand were on Deferasirox therapy.

\section{Exclusion criteria:}

- Patients or their legally acceptable representatives unwilling to share information.

- Patients who showed signs of hepatic failure (ALT levels of $>500 \mathrm{U} / \mathrm{L}$ )or had clinical or laboratory evidence of active hepatitis B or C.

- Patients who showed signs of renal failure (Creatinine clearance $<60 \mathrm{~mL} / \mathrm{min}$ ) or having serum creatinine greater than $2 \times$ Upper Limit of Normal range (ULN).

\section{Assessment}

Efficacy: To determine whether Deferasirox could maintain body iron concentrations at levels below those associated with complications from iron overload, body iron burden was assessed by observing the changes in the serum ferritin levels of the patients. Serum ferritin levels were observed and assessed every six months. Chelation therapy was considered effective if the value of most serum ferritin levels were $<2500 \mathrm{ng} / \mathrm{ml}$, whereas therapy was considered ineffective if the value of most serum ferritin levels were $\geq 2500 \mathrm{ng} / \mathrm{ml}$.

Safety: To determine the safety of Deferasirox, periodic (monthly) monitoring of ALT levels, serum creatinine, WBC counts and platelet counts were done. Safety assessments consisted of the recording and monitoring of all adverse events, serum creatinine levels, ALT levels, WBC counts, platelet counts and physical examination.

\section{Statistical methods}

Efficacy was assessed for the full analysis set, including all patients who had been successfully introduced into the study. If there was no serum ferritin value available at $3^{\text {rd }}$ month, the last available observation was used at the end of study assessment to calculate change from baseline (last observation-carried-forward analysis), thereby providing a robust yet conservative endpoint to manage with the intention-to-treat principle. A one-tailed paired $\mathrm{t}$ test is conducted to test the null hypothesis.

\section{RESULTS}

Twenty-four transfusion-dependent thalassemia patients (17 males and 7 females), aged from 2 to 12 years old (mean:7 \pm 2.8 ), were included in the study and were analyzed at baseline and follow-ups (after every 4 weeks for six months). Initial dose of Deferasirox administered to the patients was $21.32 \mathrm{mg} / \mathrm{kg}$ per day (a mean of the range 16.6 to $33.3 \mathrm{mg} / \mathrm{kg}$ per day)and was followed by prescribing $294.32 \mathrm{mg}$ per day(a mean of range $250 \mathrm{mg}$ to $500 \mathrm{mg}$ per day) of oral Deferasirox tablet once-daily before breakfast.

\section{Efficacy Outcomes}

Serum Ferritin Levels: On assessing the serum ferritin levels it was observed that out of 24 patients, 18 patients $(75 \%)$ responded positively to the chelation therapy, i.e. they were actually benefited with the chelation therapy of Deferasirox, whereas remaining 6 patients $(25 \%)$ were observed with no changes in their serum ferritin levels (Figure 1). Out of these 18 patients, 11 patients $(45.83 \%)$ were observed with serum ferritin levels 


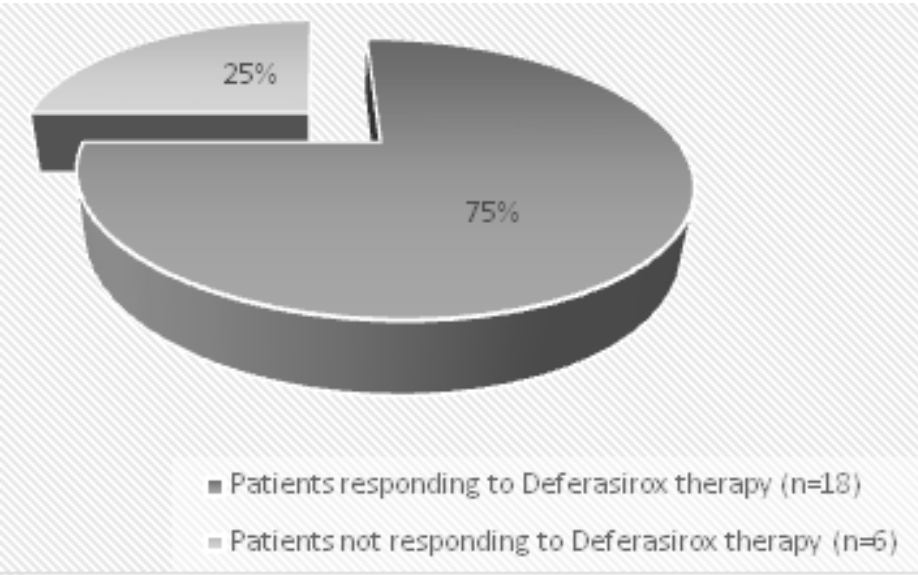

Figure 1: Efficacy percentile of Deferasirox therapy in thalassemia patients

\begin{tabular}{|c|c|c|c|}
\hline \multirow{2}{*}{ Patient } & \multicolumn{3}{|c|}{ Serum Ferritin (ng/ml) } \\
\hline & Baseline & $1^{\text {st }}$ follow-up & $2^{\text {nd }}$ follow-up \\
\hline Patient 1 & 2990 & 3055 & 2000 \\
\hline Patient 2 & 7954.8 & 17217 & 2000 \\
\hline Patient 3 & 1650 & 2545.7 & 4184 \\
\hline Patient 4 & 3450.7 & 4552 & 2000 \\
\hline Patient 5 & 1650 & 4874 & 2000 \\
\hline Patient 6 & 1856.6 & 2000 & 2000 \\
\hline Patient 7 & 1650 & 3317.2 & 2000 \\
\hline Patient 8 & 1404.5 & 1621 & 2000 \\
\hline Patient 9 & 2547 & 3582.5 & 2000 \\
\hline Patient 10 & 1665 & 2984.5 & 2361 \\
\hline Patient 11 & 3144.3 & 1561 & 1241 \\
\hline Patient 12 & 1650 & 8444 & 2000 \\
\hline Patient 13 & 1779.9 & 2000 & 1717 \\
\hline Patient 14 & 1166 & 1337.8 & 1230 \\
\hline Patient 15 & 1564 & 1648 & - \\
\hline Patient 16 & 3414 & 2859.1 & 2000 \\
\hline Patient 17 & 1650 & 1807 & 2000 \\
\hline Patient 18 & 1650 & 2011 & 2000 \\
\hline Patient 19 & 1650 & 5226 & 3486.1 \\
\hline Patient 20 & 3043 & 738 & 977 \\
\hline Patient 21 & 1427.7 & 837.9 & 634.4 \\
\hline Patient 22 & 1720.9 & 1803 & - \\
\hline Patient 23 & 3172.4 & 4698.8 & 2000 \\
\hline Patient 24 & 4196.1 & 2000 & - \\
\hline
\end{tabular}

decreased up to $2000 \mathrm{ng} / \mathrm{ml}, 5$ patients $(20.83 \%)$ were observed with serum ferritin levels below $2000 \mathrm{ng} / \mathrm{ml}$ and 2 patients $(8.33 \%)$ were observed with serum ferritin levels decreased above $2000 \mathrm{ng} / \mathrm{ml}$ (Table 1 and Figure 2). In these 18 patients, the decrease in the serum ferritin levels was found to be from $4362.5 \mathrm{ng} / \mathrm{ml}$ (range $1337.8-17217 \mathrm{ng} / \mathrm{ml}$ ) to $1869.25 \mathrm{ng} / \mathrm{ml}$ (range $634.4-$
$3486.1 \mathrm{ng} / \mathrm{ml}$ ) during Deferasirox therapy. Deferasirox was discontinued in 2 patients $(8.33 \%)$ due to decreased serum ferritin levels below $1000 \mathrm{ng} / \mathrm{ml}$ i.e. $634.4 \mathrm{ng} / \mathrm{ml}$ and $738 \mathrm{ng} / \mathrm{ml}$ respectively (Table 1).

\section{Safety Outcomes}

Safety of Deferasirox therapy was assessed mainly by observing the changes in vital organ's functioning such as kidney (renal), liver and bone marrow function. Renal functioning was assessed by obtaining serum creatinine levels, liver functioning was assessed by obtaining ALT levels mainly and bone marrow functioning was assessed by obtaining WBC and platelet counts.

ALT Levels: Out of 24 patients, 11 patients (45.83\%) were observed with increased ALT levels. In these patients, Deferasirox was discontinued until there was a reduction in the elevated ALT levels to normal levels (Figure 3).Out of these 11 patients, in 8 patients $(33.33 \%)$ Deferasirox was discontinued and was reinitiated after there was a reduction in the abnormally elevated ALT levels to the normal levels. The remaining 3 patients $(12.5 \%)$ were never been reinitiated at the period of study with Deferasirox because their abnormally elevated ALT levels had not been decreased.

Serum Creatinine Levels: In the assessment of renal functioning, the average of the pre-treatment (baseline) measurements for serum creatinine was found to be 0.5 $\mathrm{mg} / \mathrm{dl}$. The overall changes across the study period were mild; mean serum creatinine: $0.6 \mathrm{mg} / \mathrm{dl}$. As the mean changes may not reflect the individual trend in creatinine uniformly in all patients, and as normal creatinine ranges differs from male to female, data for each patient separating into two groups, males and females are given in Figure 4 and Figure 5. For 5 out of 24 (20.83\%) patients pre-treatment (baseline) and post-treatment (final follow-up) creatinine remained unchanged; for 5 out of $24(20.83 \%)$ increased slightly/mildly $(0.1 \mathrm{mg} /$ 


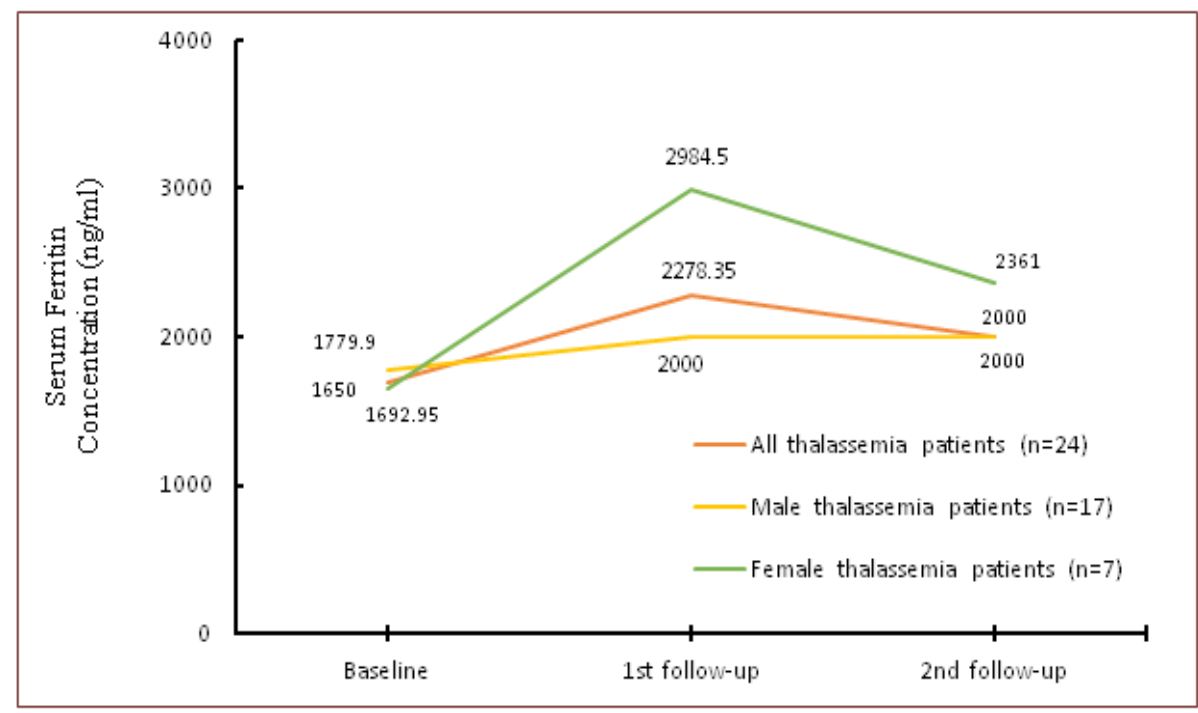

Figure 2: Median serum ferritin levels of male $(n=17)$, female $(n=7)$ and total $(n=24)$ thalassemia patients.

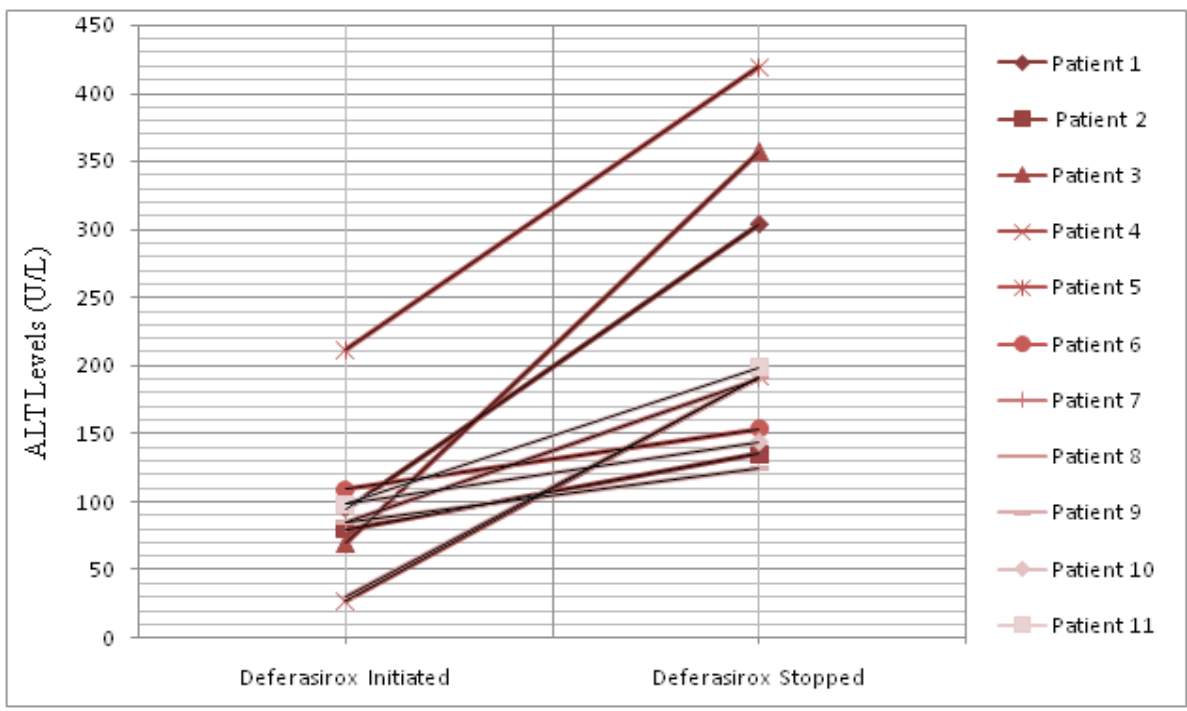

Figure 3: Increased ALT levels of thalassemia patients $(n=11)$ which lead to the stoppage of Deferasirox therapy

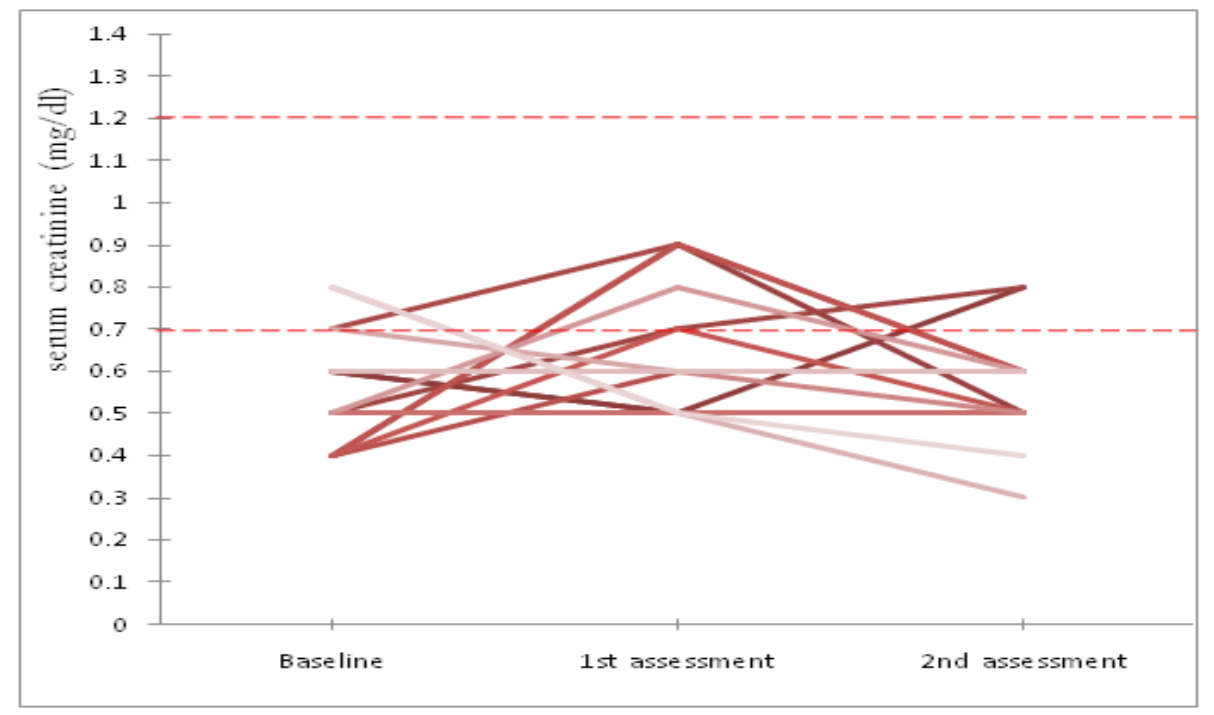

Figure 4: Serum creatinine levels in male thalassemia patients $(n=17)$ 


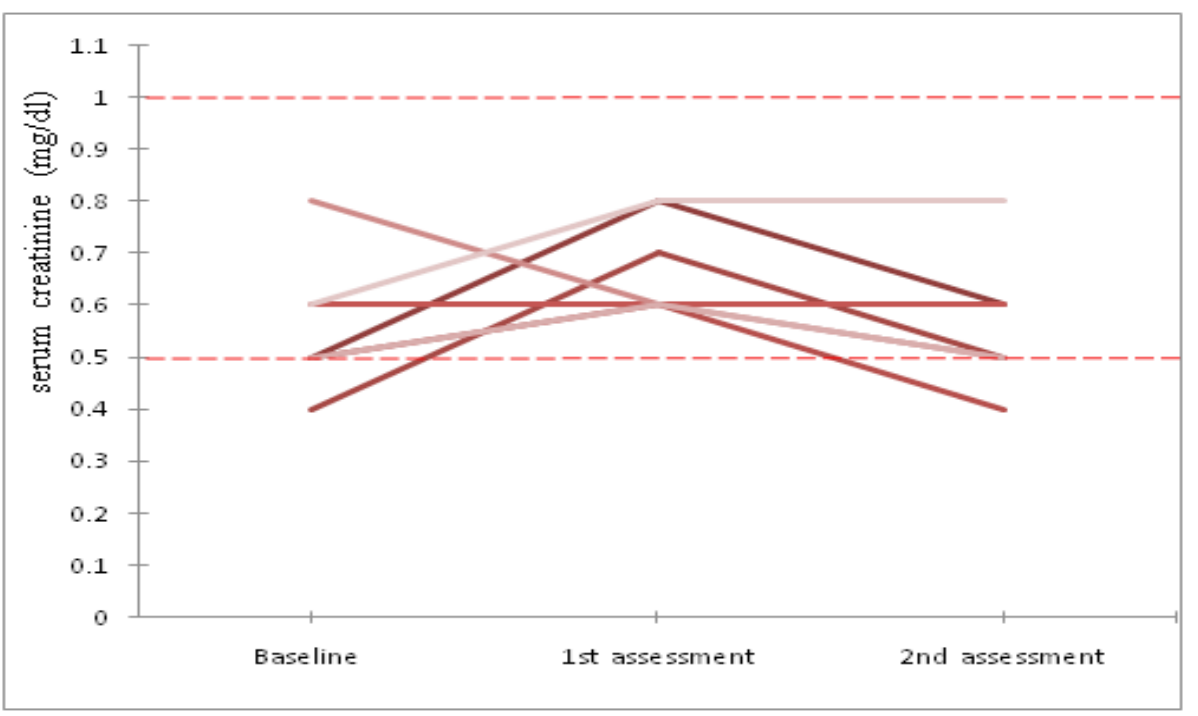

Figure 5: Serum creatinine levels in female thalassemia patients $(n=7)$

dl), 4 out of $24(16.67 \%)$ increased moderately $(0.2 \mathrm{mg} /$ dl) and 1 out of $24(4.17 \%)$ increased severely $(0.3 \mathrm{mg} /$ dl) but still was within normal values. Remaining patients were observed with decreased creatinine levels; 6 out of $24(25 \%)$ with mild/slight $(0.1 \mathrm{mg} / \mathrm{dl})$ and 3 out of $24(12.5 \%)$ with severe $(0.3,0.4$ and $0.5 \mathrm{mg} / \mathrm{dl}$ respectively). The 3 patients $(12.5 \%)$ with severely decreased serum creatinine levels were observed with the serum creatinine levels decreased below the normal levels.

WBC and Platelet counts: $\mathrm{WBC}$ and platelet counts were taken monthly for the assessment of the bone marrow functioning. In studies it was observed that Deferasirox did not affected the WBC and platelet values in any of the thalassemia patients as because the WBC counts and the platelet counts of these thalassemia patients were in the normal range throughout the study period.

\section{DISCUSSION}

Total body iron assessment: In this study, the oral chelation therapy of Deferasirox has proven to be effective in reducing iron overload to normal levels i.e. a reduction in the serum ferritin levels to the nearby normal levels. Since patients continuously load with iron as a result of their transfusion regimen, even if ferritin reaches normal levels it is unlikely that this would result in iron deficiency. Statistically, paired $t$ test was used to test the null hypothesis and it resulted that the Deferasirox therapy was efficacious.

Effect on liver function: Out of 24 patients, 11 patients $(45.83 \%)$ were observed with abnormally increase in ALT levels. 8 patients $(33.33 \%)$ out of these 11 patients Deferasirox was discontinued and was reinitiated at 10 $\mathrm{mg} / \mathrm{kg}$ per day followed by gradual escalation to a final dose of $15 \mathrm{mg} / \mathrm{kg}$ per day after a gradual reduction of the elevated ALT levels. Remaining 3 patients (12.5\%) were never been reinitiated with the Deferasirox therapy till the end of study.

Effect on renal function: In one of a study on Deferasirox, increase in serum creatinine was mild, non-progressive, and occurred in about $36 \%$ of patients. ${ }^{16}$ But here in this study, serum creatinine analysis according to gender, demonstrated that $6(25 \%)$ male and $1(4.17 \%)$ female patients were observed with decreased creatinine by $0.1 \mathrm{mg} / \mathrm{dl}, 6(25 \%)$ male patients with decreased creatinine by $0.2 \mathrm{mg} / \mathrm{dl}, 2$ male $(8.33 \%)$ patients with decreased creatinine by $0.3 \mathrm{mg} / \mathrm{dl}$ and 1 male $(4.17 \%)$ patient with decreased creatinine by $0.4 \mathrm{mg} / \mathrm{dl}$. Even if there was a heavy reduction in the creatinine levels, Deferasirox therapy was not been discontinued.

Effect on bone marrow function: In the study, it was observed that Deferasirox did not affected the WBC and platelet values in any of the thalassemia patients as because the WBC and platelet counts of these thalassemia patients were in the normal range throughout the study period.

Compliance: Managing patient expectations is the first step toward achieving long-term treatment goals. It can be challenging to keep transfusion-dependent patients complying with a chronic chelation therapy for an asymptomatic condition like iron overload. If patients are not feeling the beneficial effects of their therapy and particularly if they experience adverse events, they are not motivated to comply with the proposed treatment. One longitudinal multicenter, Italian-THAlassemia-Cost-and-outcomes-Assessment (ITHACA) ${ }^{17}$ has previously reported a decrease in patient satisfaction and acceptance of their chelation therapy by deferoxamine, as the overall benefits were not always perceived as optimal. Another 
prospective, open-label, 1-year, multicenter study in the Middle East (ESCALATOR ${ }^{18}$ demonstrated that patients had greater satisfaction and convenience with Deferasirox compared to deferoxamine, which improved compliance and overall patient well-being. One of the simplest ways to help patients overcome the compliance challenges is the maintenance of chelation calendar. This may be kept by the patients every day and can be reviewed by the treating physician at relevant time periods. ${ }^{19}$ This can help physiciansto make note of the serum ferritin results and of the remaining total body iron load indices.

Limitations: As the data available in this clinical study is very less due to less number of participated subjects been involved in the study, a large number of subjects can provide extensive results regarding the efficacy and safety of Deferasirox. So a longterm efficacy and safety assessment involving larger subject population is needed for the betterment of results and assessment.

\section{CONCLUSION}

The study demonstrated that the oral chelation therapy of Deferasirox was efficient and well tolerated in moderately iron loaded transfusion-dependent thalassemia patients. It was observed to be effective in $75 \%$ of patients (18 out of 24 patients) and has showed a manageable safety profile. The extensive availability of orally active chelator, apart from the fact that it offers the promise of easier administration, also opens up the possibility of effective therapy to target any levels of iron overloading. In future, there is a need of further long-term assessments of the efficacy and safety of Deferasirox in other iron-overloading ailments which can help forecasting the efficacy and safety data of Deferasirox in other diseased conditions.

\section{CONFLICT OF INTEREST}

I would like to declare that there is no conflict of interest of any of the authors of this article.

\section{ACKNOWLEDGEMENT}

I would like to give thanks to my colleagues \& my professors for guiding me in assessing the causal relationships of drugs \& their effects.

\section{Highlights of Paper}

- It was a prospective, observational study thatassessed the laboratory data of thalassemia patients who were on Deferasirox therapy and evaluated the efficacy and safety of Deferasirox in those patients.

- To determine whether Deferasirox could maintain body iron concentrations at levels below those associated with complications from iron overload, body iron burden was assessed by observing the changes in the serum ferritin levels of the patients.

- In this study, the oral chelation therapy of Deferasirox has proven to be effective in reducing iron overload to normal levels i.e. a reduction in the serum ferritin levels to the nearby normal levels.

- The study demonstrated that the oral chelation therapy of Deferasirox was efficient and well tolerated in moderately iron loaded transfusion-dependent thalassemia patients.

- In future, there is a need of further long-term assessments of the efficacy and safety of Deferasirox in other iron-overloading ailments which can help forecasting the efficacy and safety data of Deferasirox in other diseased conditions.

\section{Author Profile}

- Siva Shankar Reddy Y Student of M-Pharmacy (pharmacy practice) at Ratnam institute of pharmacy Nellore.

- Dr Umesh Kamarthi, Pharm-D,PV,CR, Clinical Pharmacist at BGS Global Hospitals, Kengeri, Bangalore, and Karnataka, India.

- Dr. B Kumar, M-Pharm, Ph.D, Head of Dept for Pharmacy Practice at Ratnam Institute of Pharmacy, Nellore, Andhra Pradesh, India.

\section{REFERENCES}

1. lancu TC, Neustein HB, Landing BH. The liver in thalassemia major: ultra structural observations. in Iron Metabolism, Ciba Foundation Symposium 51 Elsevier Excerpta Medica North Holland publishers 1977; 1(1): 293-316.

2. Jean G, Terzoli S, Mauri R, et al. Cirrhosis associated with multiple transfusions in thalassaemia. Arch. Dis. Child. 1984; 59(1): 67-70.

3. Borgna-Pignatti $C$, Rugolotto $S$, De Stefano $P$, et al. Survival and disease complications in thalassemia major. Ann NY Acad Sci. 1998; 850(1): 227-31.

4. Olivieri NF, Brittenham GM. Iron-chelating therapy and the treatment of thalassemia. Blood. 1997; 89(3): 739-61.

5. Olivieri NF. The ß-thalassemias. N Engl J Med. 1999; 341(2): 99-109.

6. Porter JB. Practical management of iron overload. Br J Haematol. 2001; 115(2): 239-52.
7. National Institutes of Health. Management and therapy of sickle cell disease. National Heart, Lung, and Blood Institute. $4^{\text {th }}$ edition. NIH Publication. 2002; 333(4): 96-17.

8. McLaren GD, Muir WA, Kellermeyer RW. Iron overloads disorders: natural history, pathogenesis, diagnosis, and therapy. Crit Rev Clin Lab Sci. 1983; 19(3): 205-66.

9. Prati $\mathrm{D}$, Maggioni $\mathrm{M}$, Milani $\mathrm{S}$, et al. Clinical and histological characterization of liver disease in patients with transfusion-dependent beta-thalassemia. A multicenter study of 117 cases. Haematologica. 2004; 89(10): 1179-86.

10. Engle MA, Erlandson M, Smith $\mathrm{CH}$. Late cardiac complications of chronic severe refractory anemia with hemochromatosis. Circulation 1964; 30(5): 698705. 
11. Schrier SL, Angelucci E. New strategies in the treatment of thalassemias. Annu Rev Med. 2005; 56(1): 157-71.

12. Cappellini MD, Zanaboni L. Efficacy and Safety of Deferasirox. Transfusion Iron Chelation Therapy, US Hematology. Touch Briefing 2009; 107(9): 68-73.

13. Cappellini MD, Bejaoui M, Agaoglu L, et al. Prospective evaluation of patientreported outcomes during treatment with Deferasirox or deferoxamine for iron overload in patients with beta-thalassemia. ClinTher. 2007; 29(5): 909-17.

14. Vichinsky E, Onyekwere O, Porter J, et al. A randomized comparison of Deferasirox versus deferoxamine for the treatment of transfusional iron overload in sickle cell disease. Br J Haematol. 2007; 136(3): 501-8.

15. Cappellini MD, Giardina P, Porter J, et al. Long-term safety and tolerability of the once-daily, oral iron chelator Deferasirox (Exjade1, ICL670) in patients with transfusional iron overload. Blood 2006; 108(1): 501a.
16. Cappellini MD. Long-term efficacy and safety of Deferasirox. Blood Rev. 2008; 22(1): S35-41.

17. Scalone L, Mantovani LG, Krol M, et al. Costs, quality of life, treatment satisfaction and compliance in patients with beta-thalassemia major undergoing iron chelation therapy: the ITHACA study. Curr. Med. Res. Opin. 2008; 24(7): 1905-17.

18. Taher A, Al Jefri A, Elalfy MS, et al. Improved treatment satisfaction and convenience with Deferasirox in iron-overloaded patients with betathalassemia: results from the ESCALATOR Trial. Acta Haematol. 2010; 123(4): 220-5.

19. Farmaki K, Tzoumari I, Pappa C. Oral chelators in transfusion-dependent thalassemia major patients may prevent or reverse iron overload complications. Blood Cells Mol Dis. 2011; 47(1): 33-40. 